British Journal of Psychiatry (1990), 156, 585-595

\title{
Correspondence
}

Editor: Ian Pullen

Contents: The ethics of prophylactic trials of depression/Prison suicides/Outcome in unipolar affective disorder after stereotactic tractotomy/ Forensic aspects of mental handicap/Asian patients and the HAD scale/Physical health and unmet needs/ Was Hitler a Christian?/Intestinal permeability in schizophrenia/'New long-stay' patients and social deprivation indices/Platelet MAO and 5-HT uptake in agoraphobics/'Le Suicide'/There are none so double-blind .../Malaria presenting as atypical depression.

\section{The ethics of prophylactic trials of depression}

SIR: For over twenty years psychiatrists have been aware of the importance of continuation therapy with antidepressive agents for prevention of relapse of unipolar depressive illness. Over a dozen studies of continuation therapy have shown a significant advantage for antidepressants over placebo. Montgomery et al (1988), dissatisfied with poor definition of relapse versus recurrence, have now reported a multicentre prophylactic study which seems better controlled and executed than any other to date. They have shown that patients who had been recovering for four months from major unipolar illness had a lower relapse rate $(20 \%)$ continuing for a year on fluoxetine than a control group (54\%) maintained for the same period on placebo. Fluoxetine, a relatively new drug, is the only one studied in this way so far. However, even before Dr Montgomery et als work it was apparent from the literature that the risk of relapse in the first year after recovery amounted to about $50 \%$ of placebo users and $20 \%$ in those who seemed to have kept up their medication. The serious implications of relapse for the lives of patients are apparent. Despite this knowledge, depression is notoriously badly managed in medical and, possibly, in psychiatric practice. This may be because many patients will not follow good advice or (perish the thought) because good advice is not given.

From Dr Montgomery et als own review of literature it would appear that no well-controlled study of prophylaxis or continuation has failed to show superiority of drug over placebo, irrespective of the type of antidepressant studied. It follows that subjects recruited into prophylactic trials of the Montgomery type (difficult and lengthy undertakings) should be advised that they are being asked to accept a very high risk of depressive morbidity if they consent to participate. The extent of this risk is difficult to estimate since no published accounts are available on the outcome of placebo relapsed depressives with renewed treatment. Furthermore, the fate of dropouts is seldom fully reported in follow-up studies. It is noteworthy that the exact wording of 'informed consent' forms is seldom reproduced in the text of published papers. This poses the question of whether subjects of trials such as that of Dr Montgomery et al really understand the extent of risk that they are being asked to undergo.

Is the distinction between relapse of the original episode and true recurrence after recovery (insisted upon by Dr Montgomery et al) of sufficient importance to justify one year placebo-controlled trials? To the patients, the distinction may appear as mere academic hair-splitting. We already know that these illnesses get worse, not better, over time and that relapse rates rise throughout life. Every psychiatrist should reflect on whether he/she would encourage his/her close relatives to be enrolled in prophylactic studies of the type described. It is conceivable that many will think (as I do) that the price to be paid for more prophylactic trials of classic, placebocontrolled design is unacceptable.

\section{Regional Hospital \\ University College Galway}

Ireland

\section{Reference}

Montcomery, S. A., Dufour, H., Brion, S., et al (1988) The prophylactic efficacy of fluoxetine in unipolar depression. British Journal of Psychiairy, 153 (suppl. 3), 69-76.

SIR: There is consistent support from many placebocontrolled studies that in the period following recovery on an antidepressant, further treatment is needed 
to consolidate the response. An analysis of the relapse rates on placebo of first-time depressives who would not normally be expected to develop a new episode of depression for some time shows a very similar relapse rate compared with that seen in recurrent depressives (Mindham et al, 1973). This strongly suggests that for those who stop antidepressants immediately after response, relapse in the subsequent six months is a return of the symptoms of the inadequately treated depression. It is necessary to continue treatment for at least four months following response to ensure that the episode of depression is properly treated. This simple advice is often ignored, sometimes by patients but mainly, we believe, by doctors, who seem as yet to be unaware of the importance of this. The average duration of treatment for a course of antidepressants in the UK is currently estimated to be six weeks.

The study of fluoxetine (Montgomery et al, 1988), which Professor Fahy praises did not address the issue of maintenance treatment to consolidate the response. All patients who consented to the study were treated for a six-month period with the antidepressant to ensure a persistent response. This study was attempting to address a different issue: whether long-term treatment in recurrent unipolar depression reduced the chances of the development of further new episodes of depression. This is not as Professor Fahy states, mere hair-splitting. The use of a drug to treat an episode of depression is quite different from the use of a drug to prevent a new episode of depression arising, a distinction emphasised by Montgomery (1989). There are very few good studies for secondary prophylaxis although a case can be made for fluoxetine, imipramine and possibly lithium. With amitriptyline, design flaws in the two small studies conducted leave room for doubt. For most antidepressants, we do not know whether they are effective in prophylaxis or not.

The point where we take issue with Professor Fahy is his assumption that any antidepressant will do as they all, he implies, have efficacy in maintenance and prophylactic use. He appears to find it ethical to offer long-term treatment with an antidepressant although there are doubts about long-term efficacy. We would prefer to be open with our patients and tell them that some like Professor Fahy believe that any antidepressant works while others like ourselves have doubts. We would invite the patients to participate in a carefully-controlled study to help establish this important point. We would spell out the risks and benefits in order to help them make an informed decision. This seems to be the most ethical course to adopt.

Much of Professor Fahy's belief that any drug will do is based on his understanding that no well con- trolled investigation of continuation or prophylaxis has failed to show efficacy. This approach is risky. Lithium was found to be no better than placebo in recurrent unipolar depression by Prien et al (1984). More recently, Georgotas et al (1989) reported that nortriptyline was ineffective compared with placebo whereas phenelzine was effective in a one year study of prophylactic treatment. Results like these emphasise our need for caution and suggest that we should require a convincing demonstration of long-term efficacy of an antidepressant, preferably against placebo, to avoid putting patients at risk.

STUART MONTGOMERY DAVID BALDWIN

Department of Psychiatry

St Mary's Hospital Medical School

Norfolk Place

London W2

\section{References}

Georgotas, A., MCCue, R. E., Cooper, T. B., el al (1989) A placebo-controlled comparison of nortriptyline and phenelzine in maintenance therapy of elderly depressed patients. Archives of General Psychiatry, 46, 783-786.

Mindham, R. H. S., Howland, O. \& Shepherd, M. (1973) An evaluation of continuation therapy with tricyclic antidepressants in depressive illness. Psychological Medicine, 3, 5-17.

Montcomery, S. A. (1989) Prophylaxis in recurrent unipolar depression: a new indication for treatment studies. Journal of Psychopharmacology. 3, 47-53.

-. Durour, H., Brion, S., et al (1988) The prophylactic efficacy of fluoxetine in unipolar depression. British Journal of Psychiatry. 153 (suppl. 3), 69-76

Prien, R. F., KupPeR, D. J., MAnsky, P. A., et al (1984) Drug therapy in the prevention of recurrences in unipolar and bipolar affective disorders. Archives of General Psychiarry, 41, 10961104.

\section{Prison suicides}

SIR: Dooley (Journal, January 1990, 156, 40-45) draws attention to the important problem of suicide in prison, but makes some inferences from the data which are questionable, and comes to conclusions which are disappointing in making so few recommendations for change.

Firstly, is it true that suicide in prison is increasing? The rates quoted by Dr Dooley for 1976-1987 are remarkably similar to those given by Topp (1979) for 1958-1971. It may be that in the years 1972-1975 there were relatively few suicides and that the rate has simply returned to baseline. The general characteristics of prison suicide described by the two authors are very similar, suggesting a stable rather than a changing phenomenon.

Secondly, how good is the evidence that prison suicides are a consequence of mental disorder? The 